\title{
ORDEN Y VIOLENCIA: POLÍTICAS ESPACIALES DE LA ÚLTIMA DICTADURA MILITAR ARGENTINA EN SANTA FE Y ÁREA DE INFLUENCIA (1976-1983) ${ }^{1}$
}

\section{Order and violence: spatial policies of the last argentine military dictatorship in Santa Fe and its hinterland (1976-1983)}

\author{
Gisela Ariana Rausch* \\ https://orcid.org/0000-0002-5851-3357 \\ Julieta Citroni ** \\ https://orcid.org/0000-0003-1687-9198 \\ Leticia Manassero \\ https://orcid.org/0000-0002-2035-5541
}

\begin{abstract}
Resumen
Conjugando los enfoques más recientes sobre la última dictadura militar argentina (1976-1983) con análisis pormenorizados sobre ciertos casos particulares, este artículo se propone considerar algunas de las políticas espaciales adoptadas por el régimen en la ciudad de Santa Fe y su área de influencia. Proyectos dirigidos a la vivienda social que continuaban tendencias previas, novedosos barrios privados para las élites y grandes proyectos de infraestructura son examinados con el recurso a distintas fuentes gubernamentales, informes de gestión y la prensa periódica local. A partir de los opuestos orden y violencia, estas acciones se conciben como orientadas a producir un nuevo espacio o a restaurar un pasado perdido, en el cual ciertos actores colectivos y sus intereses tenían mayor incidencia que otros, aunque no estaban exentos de contradicciones internas y algunos cuestionamientos.
\end{abstract}

\begin{abstract}
This article aims to consider some of the spatial policies adopted by the last military dictatorship in Argentina (1976-1983) at the town of Santa Fe and its hinterland. We combine more recent approaches to the regime with detailed analyses about some particular cases. Housing projects that continued previous tendencies, innovative private neighborhoods for the elites, and large-infrastructure projects are examined. Different government documents, management reports and local newspapers are analyzed. These actions, based on the opposites order and violence, are conceived as oriented to produce a new space or restore a lost past in which certain collective actors and their interests had more influence than others, but they were not exempt from internal contradictions and questioning.
\end{abstract}

$<$ Dictadura $><$ Planeamiento urbano $><$ Políticas espaciales $><$ Orden $>$

$$
<\text { dictatorship }><\text { urban planning }><\text { spatial policies }><\text { order }>
$$

Recibido: 14/06/2020//Aceptado: 10/11/2020

\footnotetext{
1 Este artículo reúne los resultados de tres investigaciones: Rausch, Gisela: "Los grandes proyectos de infraestructura hídrica y los procesos de reconfiguración territorial (Argentina 1950-2000)"; Proyecto CIC-CONICET (2013-2019); Citroni, Julieta: "Modos de control social en regímenes dictatoriales. Las políticas de ordenamiento urbano en Santa Fe y Rosario, 1976-1983" (Tesis de Doctorado en Ciencia Política en curso, UNR) y Manassero, Leticia: "Producción de espacio y regulación: la construcción de los barrios privados en el periurbano santafesino (1975-2003)" (Tesina de grado, UNL,2019).
}

\footnotetext{
* Instituto de Estudios Críticos en Humanidades (CONICET/UNR), Argentina, gsrrsch@gmail.com

** Centro de Estudios Sociales Interdisciplinarios del Litoral (CESIL), Facultad de Humanidades y Ciencias, Universidad Nacional del Litoral, Santa Fe, Argentina, julietacitroni@gmail.com *** Universidad Nacional del Litoral (UNL), Santa Fe, Argentina, letmanassero@hotmail.com
} 
Rausch, Citroni y Manassero. Orden y violencia: políticas espaciales de la última dictadura militar argentina en Santa...

\section{Introducción}

Este artículo parte de la premisa general que sostiene que la última dictadura militar en Argentina, desplegada entre los años 1976 y 1983, tuvo características singulares y diferenciales respecto de los gobiernos dictatoriales precedentes. Esta singularidad estuvo dada por una voluntad de refundación total e irreversible de la sociedad argentina, junto con un plan de exterminio de la disidencia política expresado en procedimientos y acciones de represión y violencia. Puede decirse que la última dictadura militar argentina desplegó una serie de estrategias y tecnologías de poder, orientadas a tales fines, los cuales se pretendían alcanzar a través de, por un lado, la instalación de una idea específica de orden, y por el otro, del ejercicio efectivo de la violencia mediante una diversidad de estrategias, procedimientos y prácticas. Esta forma particular de gobierno adquirió consistencia en un conjunto heterogéneo de instituciones creadas o reconfiguradas, disposiciones y procedimientos en varios órdenes (político, económico, espacial, por mencionar algunos), así como en prácticas discursivas y espaciales específicas.

Para el caso de Santa Fe y su área de influencia ${ }^{2}$, las propuestas y disposiciones espaciales fueron sistematizadas en el "Plan Director" de 1980. Si bien los procedimientos para establecer un orden territorial a través del Plan no constituye una característica específica de esta dictadura - por cuanto esa idea se encuentra en los postulados básicos del Urbanismo moderno y del Planeamiento-, lo específico de este gobierno fue colocar dichos postulados al servicio de ese plan de transformación total de la sociedad. Esto implicaba, entre otras prácticas, reconfigurar el espacio regional así como también, a escala urbana, los espacios que habitaba y de los que hacía uso la población. En tal sentido, puede considerarse el espacio como vehículo relevante para el ejercicio del poder dictatorial. Más aún, puede decirse que el espacio fue "el medio y el lugar para crear de manera autoritaria una nueva sociedad" (Salamanca Villamizar y Colombo, 2019, p. 25).

A partir de lo expuesto, este artículo reúne tres investigaciones sobre prácticas y políticas espaciales (de escala urbana y regional) de la última dictadura militar en la ciudad de Santa Fe y su área de influencia. El objetivo principal es exponer y analizar, en perspectiva histórica, tres casos donde las prácticas espaciales constituyeron el vehículo de esa voluntad de orden y refundación nacional, promovida por dicho gobierno. Orden que se lograba, en gran parte, a través de la violencia y del aparato represivo que desplegó. Las respectivas investigaciones se han sustentado en el análisis documental mediante la utilización de una variedad de fuentes que posibilitaron la construcción histórica del "objeto urbano-territorial". Entre las más relevantes pueden mencionarse: informes técnicos provenientes de oficinas gubernamentales, documentación de planificación urbana y proyectos (estatales y privados), leyes, normativas y reglamentaciones urbanas, fuentes hemerográficas, folletería de difusión y publicaciones especializadas. Dada la complejidad del objeto urbano, se aspira a encarar el problema de investigación desde

\footnotetext{
2 Nos referimos al área difusa que, si bien no corresponde estrictamente al ejido urbano de Santa Fe, mantiene con éste estrechas relaciones funcionales. Entre las localidades que hacia finales de la década de 1970, tenían dichas relaciones, podemos mencionar: Santo Tomé, San José del Rincón, Colastiné, Monte Vera y Sauce Viejo.
} 
distintos ángulos, multiplicando además los registros y las fuentes desde los cuales habitualmente se examina esta etapa de la historia argentina, densificando los materiales existentes sobre un espacio de investigación altamente provechoso y marcado por renovados análisis actuales.

El trabajo en el cual convergen estas tres investigaciones sobre distintas propuestas espaciales llevadas adelante por la última dictadura militar pretende incorporar una mirada más amplia a los estudios — hasta ahora fragmentarios - sobre las políticas espaciales de dicho gobierno en una ciudad media de la región Centro de Argentina, capital de la provincia de Santa Fe. Con esto, se intenta observar las especificidades de dichas políticas en la ciudad y territorio ampliado, así como también destacar la coherencia de las mismas dentro del plan de transformación social general pergeñado por la dictadura.

El artículo se desarrolla en tres apartados principales: en el primero se desarrolla un marco general teórico-histórico: por un lado, se presentan algunos conceptos y enfoques que han posibilitado la lectura de los casos estudiados, y por el otro, se establecen algunas coordenadas históricas a partir de las cuales, dichas propuestas espaciales, tuvieron lugar. El segundo apartado desarrolla los tres casos estudiados: 1) las políticas dirigidas a satisfacer la demanda de vivienda de interés social; 2) las políticas en el espacio suburbano, a partir de tres proyectos de enclave habitacional tipo barrio jardín o country; y 3) dentro de las políticas de escala regional, se analiza el Proyecto Hidroeléctrico Paraná Medio (PHPM) como nodo de una propuesta infraestructural de energía y transporte. En el tercer apartado se presentan las conclusiones.

\section{Orden y violencia: políticas en el espacio santafesino durante la última dictadura militar}

El estudio de la dimensión espacial y proyectual de las políticas llevadas adelante por la última dictadura militar posibilita encontrar matices en sus prácticas y diversidad en sus aproximaciones que, desde otras dimensiones, podrían parecer contradictorias. Las iniciativas públicas, que ideológicamente pueden concebirse orientadas en una determinada dirección, se complejizan al espacializarse en un territorio que ya posee sus propias lógicas, y en el cual existen actores diversos que actúan estratégicamente en función de sus propios valores e intereses, así como también jerarquías y relaciones de poder ya establecidas. Como han señalado Rodríguez y Di Virgilio (2011, p. 22), "cuando la política pública se encuentra con el territorio, las particularidades de este último contribuyen a redefinir el curso de la acción en la medida en que sobreimprimen a su desarrollo la impronta de una configuración socioterritorial particular".

En el caso de muchos proyectos ejecutados por la última dictadura militar, puede observarse que la mayor parte eran propuestas de gobiernos anteriores, guardadas en las oficinas técnicas, que fueron retomadas estratégicamente. En general, el gobierno dictatorial dio continuidad a algunos proyectos existentes y no concretados, pero los reformuló en función de sus objetivos políticos (Alonso y Citroni 2008). Debe considerarse que este gobierno, por un lado, poseía un aparato represivo lo suficientemente fuerte para la imposición de nuevas realidades espaciales, y por 
Rausch, Citroni y Manassero. Orden y violencia: políticas espaciales de la última dictadura militar argentina en Santa...

el otro, necesitaba legitimar su poder autoritario creando consenso social a través de manifestaciones evidentes (Águila, 2008). En este sentido, puede hablarse de un uso político estratégico de las ideas y los proyectos espaciales preexistentes, en especial las provenientes del planeamiento urbano. Como ha señalado Ballent (2009, p. 20), "técnica y política constituyen dos miradas distintas pero vinculadas sobre los mismos objetos, los espacios del habitar en sus distintas escalas" ya que la técnica es mediadora de las relaciones entre política y sociedad.

Por otro lado, además, la observación de las políticas y las prácticas espaciales de este gobierno en una misma ciudad ha posibilitado colocar en relieve las divergencias ideológicas internas al mismo gobierno que las proponía. Así, por ejemplo, como veremos en los casos expuestos a continuación, mientras que el PHPM era promovido por las Fuerzas Armadas (FFAA) con un discurso fuertemente estatista y desarrollista -y por momentos, bélico-, por el contrario, los barrios privados suburbanos se fundaban en ideas de corte neoliberal, tomando el modelo de suburbio estadounidense, y concretándose por la creación de un laissez faire espacial, es decir, con políticas más próximas a las defendidas por el Ministerio de Economía liderado por José Martínez de Hoz. Tales aparentes contradicciones ideológicas pueden comprenderse a la luz de lo postulado por Canelo (2016) respecto de la conformación heterogénea del gobierno dictatorial: 1) según la autora, la fracción "dura" estaba constituida por los "generales más paradigmáticos del terrorismo de estado" (p. 49) y poseía alta gravitación en las Fuerzas Armadas. Sus adeptos eran ideológicamente anticomunistas, antiperonistas y católicos, mientras que en lo económico defendían las ideas desarrollistas y estatistas ${ }^{3}$; 2) la fracción "politicista" tenía, por el contrario, un posicionamiento pragmático respecto de los objetivos de la dictadura, articulando con partidos políticos y sindicatos. Sin embargo, señala Canelo (2016), compartían con la fracción "dura" su oposición a la política económica liberal; y 3) la fracción "moderada" tenía un doble rol consistente en moderar la interna entre las fracciones anteriores y articular la lucha antisubversiva con la reforma económica liberal (p. 52).

Respecto a esta conformación de la dictadura y sus prácticas espaciales coincidimos con Jajamovich y Menazzi (2012, pp. 12-13) cuando aseveran que "el cruce de lógicas políticas y técnicas contradictorias y las internas burocráticas cobran particular visibilidad en lo urbano, ya que no son solo las políticas específicamente urbanas las que tienen efectos territoriales, sino también, y con particular fuerza, ciertas medidas económicas y ciertas políticas sociales". Particularmente, en el ámbito de lo urbano las políticas espaciales llevadas adelante estuvieron en estrecha consonancia con las premisas moralizantes de orden y limpieza. Los diversos proyectos que fueron concretados en las ciudades, las intervenciones de mejora y ordenamiento, la construcción de infraestructura y el desarrollo de las oficinas de planificación expresaron su contracara en la violenta erradicación de villas miserias, el desalojo y la expulsión de todo lo considerado popular, la apropiación de tierras y el control de las áreas rurales

Como veremos más adelante, el ministro de Planeamiento pertenecerá a esta fracción. 
(Citroni, 2011; Jajamovich y Menazzi, 2012; Catullo, 2016; Oszlak, 2017 (1991); Brites y Salamanca y Colombo, 2019).

Si bien tales ideas ya estaban en los postulados del urbanismo moderno y el planeamiento urbano de las primeras décadas del siglo XX, se reconoce con Oszlak (2017, p. 41) que "la adopción de estas políticas puso crudamente de manifiesto la vigencia, a nivel de las distintas instancias de decisión del estado, de una nueva concepción sobre la jerarquía del espacio urbano, la función de la ciudad y el lugar que debían ocupar en ella los sectores populares". Para estos objetivos, los postulados del planeamiento urbano le eran especialmente útiles: zonificación urbana, expulsión de las zonas industriales a las periferias, privilegio de las áreas residenciales destinadas a la clase media, valoración y recuperación de espacios verdes, erradicación de villas miserias y sistematización del transporte urbano y regional ${ }^{4}$.

En la ciudad de Santa Fe, el Plan Director aprobado en 1980, sistematizó la visión espacial de este gobierno en la jurisdicción municipal y su área de influencia. Este Plan, que constituía una herencia de gobiernos precedentes ${ }^{5}$, concretó —en el aspecto normativo más que propositivo- esta voluntad de ordenar el espacio de la ciudad y de organizar las conexiones en la región. Como dan cuenta los estudios sobre el mismo (Alonso y Citroni, 2008; Citroni, 2011; Rausch, 2010 y 2019), el Plan organizaba normativamente el espacio urbano y perfilaba, a través de una serie de proyectos de infraestructura (sistematización ferro-vial de las conexiones en la escala regional, una conexión subfluvial entre Santa Fe y Paraná y una represa con central hidroeléctrica) un espacio regional, que para ese momento en la ciudad, constituía una innovación ${ }^{6}$.

Una cuestión clave de las políticas espaciales desplegadas en esta dictadura, en el ámbito de lo urbano, fue la búsqueda de consenso social y la participación de los ciudadanos en el ámbito municipal, a propósito de algunos proyectos. Como ha señalado Canelo (2016), el ámbito municipal se convirtió en el espacio para el ejercicio de una micropolítica de la dictadura. En efecto, en varias ocasiones los proyectos del gobierno, como veremos más adelante, se promovían a través de audiencias públicas, reuniones de promoción y debate con los ciudadanos usuarios, técnicos especialistas, así como también apelando a su promoción bajo la idea de bien público con la finalidad de construir consenso social respecto de las obras a ejecutar. Para el caso de Santa Fe, un vocero privilegiado del sector social que adhería a las propuestas de la dictadura fue el diario El Litoral, en el cual se promovían frecuentemente las propuestas urbanas municipales (Alonso y Citroni, 2008). Así también en el Plan Director se alentaba "un

\footnotetext{
${ }^{4}$ Sobre la relación entre los postulados del Planeamiento regional y la planificación de la última dictadura militar, puede verse: Rausch (2019). Sobre las características que adoptó el planeamiento regional en Argentina: Pastor (1947); Rigotti (2004); Mazza (2008); Gutiérrez (2016).

5 El Plan Director que se aprobó por Ordenanza No 7871 del 14 de agosto de 1980, contenía modificaciones respecto de las propuestas anteriores, volcadas en el llamado Plan Nardi. En éste, que sólo se materializó en un folleto, el plantel técnico de la oficina de planeamiento poseía otra conformación.

6 A pesar de que la noción de planeamiento regional en Argentina, ya circulaba por algunas oficinas técnicas hacia la década de 1940, en Santa Fe recién se incorpora en 1966 cuando se le da nuevo impulso a la Dirección de Planeamiento Urbano municipal, que existía desde 1950 (Citroni, 2019). El Plan Director de 1980 sería el primero que incorpora la idea de región y espacio regional.
} 
Rausch, Citroni y Manassero. Orden y violencia: políticas espaciales de la última dictadura militar argentina en Santa...

crecimiento ordenado y armónico" cuya finalidad era "propender al bienestar de sus habitantes". Dicho bienestar se entendía en términos de orden, expulsión de lo popular y cohesión nacional.

El sentido refundacional que constituyó la clave de la estrategia política general (Ferrer, 2004; Canelo, 2016; Oszlak, 2017), también orientó las políticas espaciales en este período. Orden y limpieza se convirtieron en valores estratégicos materializados en los proyectos urbanos de este gobierno, que se concibió heredero de la Generación del ' 80 y persiguió la fundación de una Nueva República (Canelo, 2016). La insistencia en conjurar el caos urbano, que esta dictadura atribuía a los gobiernos precedentes, principalmente al peronismo, se sustentaba en una idealización de un pasado ordenado que, dentro de esta lógica, era necesario recuperar. Según esta particular visión, dicha recuperación se alcanzaba, por un lado, con un gobierno representante de las elites (sociales, económicas y políticas) que expulsara todo aquello considerado popular, y por el otro, a través de la imposición de ciertos valores morales, asociados a una idea de Ser Nacional, que encontraban su vehículo en las políticas y las diversas prácticas que la dictadura llevó adelante. Así, como veremos en el primer apartado, las acciones de limpieza urbana se manifestaban en la erradicación de villas miserias y tuvo como solución la construcción de grandes complejos de vivienda masiva. Por el contrario, las elites encontraban espacios de habitabilidad innovadores, como el modelo de barrio jardín suburbano.

Por otra parte, la intención que tuvo esta dictadura por establecer un antagonismo con gobiernos anteriores, apelando a la modernización del territorio, fue acompañada en el ámbito de la planificación por la incorporación de la idea de región en la organización del espacio (Rigotti, 2003; Mazza, 2008; Rausch, 2010). Esta idea encontró una de sus manifestaciones en los grandes proyectos de infraestructura. Así, las autopistas y los puentes se convirtieron en la posibilidad de acrecentar la velocidad de las conexiones entre los centros urbanos, los cuales pasaban a funcionar como "nodos" regionales. Mientras que, por su parte, las centrales productoras de energía (térmica, nuclear o hidroeléctrica) prometían intensificar el ritmo industrial y abastecer de energía los centros urbanos en crecimiento. De ese modo, se efectivizaba la tan perseguida modernización, que en la visión de este gobierno se había puesto en pausa durante los gobiernos precedentes (Rausch, 2019).

Como exponemos en el tercer apartado, los grandes proyectos de infraestructura se convirtieron, muchas veces, en vehículo de las aspiraciones expansionistas de las FFAA, cuyos ideales nacionalistas y desarrollistas distaban de la visión pragmática y liberal que sustentaba los proyectos urbanos. La amenaza imperialista de Brasil, que en el discurso del gobierno pretendía avanzar sobre territorio argentino a través de los ríos, se constituyó en un motivo para la promoción de centrales hidroeléctricas, las cuales se justificaban en el objetivo de defender y fortalecer la soberanía territorial.

\section{Políticas de ordenamiento urbano dirigidas a la vivienda social}

Una de las políticas contenidas en el Plan Director de Santa Fe consistía en "propender a la solución del problema habitacional de los sectores de la población 
de ingresos bajos o medios, como medio de contribuir a mejorar las condiciones de vida y eliminar los asentamientos marginales" (p. 105) ${ }^{7}$. En otras palabras, preveía la erradicación de las villas miseria y, por derivación, de quienes las ocupaban, dando continuidad a tendencias más generales, prevalentes al menos desde los años '60. En esta línea se comprende uno de los aportes del temprano artículo de Cuenya (1992), en el sentido de que los códigos urbanos sancionados en aquellos años por casi todas las municipalidades argentinas iban en estrecha correspondencia con la intervención del Estado en materia de vivienda. De allí que se constituyeran en valiosos instrumentos del sistema jurídico, institucional y financiero que conformaba la política habitacional.

Siguiendo a Van Poepelen (2006, p. 212), estas acciones implicaron el traslado de población "bajo el concepto de control social instaurado por el gobierno de facto", con su consecuente relocalización en grandes complejos habitacionales "financiados por el Estado con fines de disciplinamiento". El autor se refiere a aquellos erigidos por la operatoria que articulaba el Fondo Nacional de la Vivienda (FONAVI), dependiente de la Subsecretaría de Desarrollo Urbano y Vivienda de la Nación, el Banco Hipotecario Nacional y el ente local correspondiente. En Santa Fe, la Dirección Provincial de Vivienda y Urbanismo (DPVyU) colaboró activamente en la financiación, aportando buena parte del presupuesto. Creado en 1972, el fondo sufrió importantes modificaciones en su estructura y financiamiento durante este período ${ }^{8}$; lo más significativo fue que pasó a estar dirigido a las familias de recursos insuficientes, antes desestimadas por su escasa capacidad de ahorro (Ballent, 2014).

En cuanto a la ejecución de los programas y dadas las características de construcción masiva que implicaban, éstos quedaron fundamentalmente a cargo de un reducido grupo de empresas de capital más concentrado, entre las que se contaban algunas de origen extranjero. Con Pucciarelli (2004) se recuerda que eran conocidas como patria contratista en la jerga política, tenían gran poder e influencia sobre el aparato estatal y éste, a su vez, las favorecía con sus decisiones. Es que "el sostén de este esquema de política habitacional encuentra su explicación en el cambio que se operó en el Estado durante la década de los setentas, como expresión de los nuevos patrones de dominación política que surgieron [...] con las dictaduras y la coalición de intereses que ellas representaron: sectores burocráticos civiles y militares, capital internacional radicado en la sociedad y las capas más dinámicas de la burguesía nacional” (Cuenya, 1992, p. 39).

Los conjuntos construidos constituyeron las mayores propuestas de solución al entonces acuciante déficit habitacional concebido, según Baliero (1983), más en términos cuantificables, como unidades concretas, que como calidad y hábitat. Estaban destinados a satisfacer las necesidades de la vivienda de interés social, concepto que remite a una "habitación de bajo costo, destinada a sectores sociales medios y bajos, que a partir de la década de 1940 se encuentra asociada a la acción del Estado" (Ballent,

${ }^{7}$ Del mismo proviene el diagnóstico de áreas marginadas existentes en la ciudad, que cierra el presente como Figura 1.

8 Leyes nacionales $N^{\circ} 19929$ del 3 de noviembre de 1972 (Creación del Fondo Nacional de la Vivienda) y 21581 del 26 de mayo de 1977 (Régimen de financiamiento del Fondo Nacional de la Vivienda). 
Rausch, Citroni y Manassero. Orden y violencia: políticas espaciales de la última dictadura militar argentina en Santa...

2004, p. 176). Por tanto, "la unidad de vivienda, se constituía así en un sector de capital protegido de las reglas de libre mercado" aunque, al mismo tiempo, promoviera el acceso de aquellos grupos al sistema de propiedad privada (Fernández Wagner, 1999, p. 125). De acuerdo con Oszlak (2017), esto suponía una nueva concepción del espacio urbano, la función de la ciudad y el lugar que en ella les correspondía a los sectores populares. En definitiva, "la estructura espacial urbana tiende así a reproducir la estructura social y yuxtaponerse a ella" (Oszlak, 2017, p. 36).

Si bien el Plan Director (p. 48) consideraba a estas políticas como "una perspectiva optimista de solución para la mayoría de la población", por cierto no pudieron corregir el déficit de sus destinatarios de recursos insuficientes. Entre otras dificultades, se reconoce la escasa disponibilidad de espacios adecuados a la dimensión de los proyectos. Cuestión que se ve bien reflejada en el emplazamiento de los mismos, resuelto por la simple existencia de tierras fiscales, todas bajas y rellenadas, periféricas en relación al ejido urbano. Lo que, en las opiniones oficiales de la época, no constituía un problema sino una privilegiada cercanía a las conexiones viales. A posteriori, estos complejos serían considerados unas "determinaciones de alto impacto en la estructura urbana [...] en sectores desaconsejables de la ciudad" (Municipalidad de Santa Fe, 2002, p. 104).

En palabras de Ballent (2014, p. 308), "el problema de la alteridad con respecto a la ciudad tradicional puede ser visto también como una fuerte apuesta a las posibilidades de transformación de la ciudad y la sociedad existentes, que, aunque desmentidas por la historia posterior, se consideraba un dato insoslayable en el momento del proyecto de estas obras". Así, el complejo Las Flores II (1.306 unidades habitacionales, 1978-1983) se edificó al norte de Santa Fe, en un distrito de trabajadores y de quintas, contiguo a su homónimo antecesor ${ }^{9}$. De allí que su particular diseño y magnitud produjeran el siguiente efecto en la prensa local: "hasta no hace mucho un barrio apacible [...], va en camino de convertirse en verdadera ciudad satélite, por la acumulación de pobladores en un radio relativamente reducido"10. A pesar de que la ubicación elegida contrariaba las pretensiones del Plan Director, era hacia allí adonde se dirigía el crecimiento urbano (Rausch, 2019) y hoy ambos conjuntos se encuentran integrados a la trama de la ciudad.

Por su parte, el barrio Centenario (1.289 unidades, 1978-1982) fue levantado en el borde sur, luego de la paulatina recuperación de los bañados del río que amenazaba continuamente la zona. Estas tareas de defensa, emprendidas desde 1950, incluyeron el desalojo de las viviendas precarias que ocupaban familias de obreros ${ }^{11}$. A fines de 1977, la Dirección Provincial de Vivienda se encontraba preparando la documentación técnica para adjudicar la provisión de terreno, proyecto y ejecución de un agrupamiento urbano que sumara 1.000 viviendas o más, con su correspondiente equipamiento e infraestructura

\footnotetext{
9 Éste fue un emprendimiento de la DPVyU que no alcanzaba las 600 unidades e incluía equipamiento urbano, gestionado por medio de distintas líneas de financiamiento, desde 1965 hasta 1976. A lo largo de tan extenso período, se detectan diferentes empresas constructoras y ritmos de trabajo, junto a un sinfín de inconvenientes.

${ }^{10}$ En Las Flores, una ciudad dentro de la ciudad, reclama importantes servicios. (5 de julio 1974). El Litoral, p.4.

${ }^{11}$ Los desalojos en Barrio Centenario. (14 de enero de 1950). El Litoral, p. 3.
} 
de servicios públicos ${ }^{12}$. De aquel acto resultó elegido este sector, probablemente por su original ubicación respecto de las demás propuestas. Sin embargo, rápidamente se decidió agregar otra localización, ampliando los alcances de la licitación y solicitando autorización para superar el cupo anual asignado por la Subsecretaría de Desarrollo Urbano de la Nación a la provincia.

Se trataba del barrio El Pozo (1.476 unidades, 1979-1987), alzado en una amplia área aislada del tejido urbano, sobre una de las márgenes de la laguna Setúbal o de Guadalupe. En este caso, se repitió el mismo patrón que en el anterior: en distintas ocasiones, se desarmaron las villas allí existentes y sus habitantes fueron trasladados compulsivamente hacia Yapeyú ${ }^{13}$. También estos terrenos tuvieron que ser refulados y saneados, lo que estaba ocurriendo desde 1971, con la erección de la Ciudad Universitaria contigua. Éste fue el último de los innumerables proyectos que se barajaron para ese sector desde principios de siglo y que, en aquel momento, se explicaba en la tendencia de expansión hacia el este deseada por el Plan Director para la ciudad y en el marco del PHPM. Por lo demás, este complejo debió sortear una serie de dificultades en las que se mezclaron los intereses de las contratistas y circunstancias climáticas adversas, con los devenires y desinteligencias característicos de toda obra pública en Argentina. Todo lo cual dio como resultado el período más prolongado de construcción, con momentos de paralización completa de los trabajos.

Retomando la definición de Ballent (2004, p. 176), la vivienda de interés social suponía un "conjunto de problemas económicos y sociales propios de las sociedades modernas". Para el período que nos ocupa, revelaba "dos características segregatorias: una, su diferencia tipológica con respecto al resto de la ciudad, y la otra su homogeneidad interna en extensiones relativamente grandes". En la evaluación crítica de las acciones del gobierno nacional en la materia realizada en aquellos años, se puede leer que "la experiencia demostró que si bien la concepción y fines de la Ley fueron atinados, las modalidades de operación y administración del Fondo resultaron poco eficientes" (Baliero, 1983, pp. 151 y 79). Como se verá a continuación, lo mismo ocurría con los planes de vivienda que desarrollaban en paralelo las gestiones comunal y provincial, aunque en una escala mucho más reducida, a menor ritmo y con ciertas características particulares.

En respuesta "a los objetivos y política de carácter prioritario trazado por esta Intendencia, por cuanto los mismos constituyen una verdadera Acción Social", a mediados de 1976 se elaboró el Plan integral de erradicación de villas de emergencia $y$ rancheríos, en cuyo marco se erigieron pequeños conjuntos en terrenos comunales ${ }^{14}$. De ellos cabe destacar la segunda entrega de 38 unidades programada para un sector

${ }^{12}$ Resolución DPVyUN 16399 del 26 de julio de 1978. Éste y otros documentos que permiten conocer el devenir del proceso, se encuentran almacenados en el archivo central de esa repartición.

${ }^{13}$ Iniciativa de la municipalidad para erradicar el cinturón de "villas miseria" de la ciudad. ( 22 de enero de 1967). En una reunión informativa destacó el intendente el cumplimiento de etapas. (24 de septiembre de 1976). El Litoral, p. 4.

${ }^{14}$ Sancionado por Ordenanza N ${ }^{\circ} 7192$ del 5 de agosto de 1976 y aprobada ésta por los Decretos provinciales $\mathrm{N}^{\circ} 3217$ del 13 de octubre y 3869 del 25 de noviembre de 1976. Entre otras situaciones a regular, se destaca la intención de desocupar los vagones ferroviarios abandonados y diseminados por la ciudad. 
Rausch, Citroni y Manassero. Orden y violencia: políticas espaciales de la última dictadura militar argentina en Santa...

de Villa Yapeyú, en el noroeste de la ciudad. Ésta había sido una zona deshabitada hasta comienzos de la década del ' 50 , cuando se la definió como villa de emergencia y fue acogiendo a población desplazada de otros lugares, de forma sostenida a lo largo del tiempo ${ }^{15}$. Lo interesante de esta nueva experiencia autoritaria fue que se trataría "de viviendas económicas mediante la aplicación de un sistema de trabajo de ayuda mutua y/o del esfuerzo propio", esto es, trabajo en la obra por parte de los futuros adjudicatarios. Además, incluía un reglamento que, entre otras cuestiones, pretendía ajustar las conductas a normas convenidas con la municipalidad ${ }^{16}$.

En tanto las villas erradicadas estaban "ubicadas en zonas relativamente céntricas de la ciudad y en lugares de penetración" o "en su mayoría eran una manifestación positiva y de hecho del problema de la inundación"17, es probable la confluencia de esta iniciativa con el Plan de Erradicación de Villas de Emergencia (PEVE) instituido en 1967. Justamente, éste tuvo su primera aplicación en Villa Yapeyú, a partir de marzo del año siguiente ${ }^{18}$. Más allá de la análoga denominación, eran similares los objetivos perseguidos: "no solo se atendía [...] a un problema social" sino también el "disponer de terrenos ocupados por viviendas precarias para obras públicas y privadas; y el control de un grupo social organizado que era visto como potencialmente peligroso" (Ballent, 2014, pp. 303-304). Además, de acuerdo con Gomes (2018, p. 76), lo caracterizaba "un discurso fuertemente higienista y una impronta profiláctica social urbana, que se profundizó durante la última dictadura militar argentina".

A escasos días de asumir el nuevo régimen, los medios reconocían que la "sustitución de viviendas que ofenden la condición humana por otras que llenan los requisitos indispensables de sanidad y convivencia civilizada [...] comenzó durante la anterior intervención militar alcanzando niveles de importancia durante la gestión del gobierno recientemente desplazado" ${ }^{19}$. Al mismo tiempo, señalaban que era preciso continuar y profundizar esa labor. Cuatro años después, el Plan Director (1980, pp. 48 y 105) presentaba su propio diagnóstico: las "viviendas inaptas [por hacinamiento y/u obsolescencia] y ranchos, en su mayoría villas de emergencia, que totalizan una cantidad de 15.636 unidades, constituyen el déficit habitacional más agudo". Prácticamente, era un $20 \%$ del total. Atento a ello, una ex Dirección de Vivienda Municipal ${ }^{20}$, pretendía "mejorar la situación actual de los asentamientos marginales, en lo concerniente a sus

${ }^{15}$ Villa Yapeyú, barrio en pleno desarrollo, puede ser base de una interesante experiencia social. (12 de julio de 1964). El Litoral, p. 4.

${ }^{16}$ Las citas de este párrafo provienen de los considerandos de la Ordenanza № 7552 del 9 de octubre de 1978.

${ }^{17}$ Se cumplió la reunión del intendente con representantes de las fuerzas vivas. (30 de septiembre de 1978). El Litoral, p. 4. Viviendas del plan de erradicación de villas de emergencia, se entregaron. (6 de enero de 1979). El Litoral, p. 4.

${ }^{18}$ Por Ley nacional № 17605 (Plan de promoción social, construcción y financiación de viviendas) y Decreto provincial $\mathrm{N}^{\circ} 9774$ del 29 de diciembre de 1967, se acordaron los términos de funcionamiento y financiamiento del programa. Dentro del mismo, la cartera santafesina tenía a su cargo la ejecución de las obras.

${ }^{19}$ El plan de erradicación de villas de emergencia merece un enfoque integral. (30 de marzo de 1976). El Litoral,p.3.

${ }^{20}$ Creada en 1970, se encontraba prácticamente disuelta y su personal reducido desde 1977. Reconstrucción realizada por el arquitecto Oscar Berlincourt, director del área desde su rehabilitación en 1993 y, anteriormente, parte de sustaff. 
condiciones de habitabilidad, servicios e infraestructura", atendiendo especialmente a la promoción comunitaria.

En estas páginas se recorrieron algunas de las soluciones al problema habitacional aplicadas en la capital santafesina entre 1976 y 1983, dando continuidad a ideas y tendencias previas pero con sus propias notas y acentos particulares. Fueron decisiones que insumieron cuantiosas inversiones y produjeron hondas transformaciones en todo el tejido urbano y social, observables en el presente. De allí que puedan ser entendidas como la culminación de una prolongada aspiración "de expresar la 'imagen de modernidad urbana' donde subyacía la concepción autoritaria que, una vivienda nueva modelaría la vida de los pobres" (Fernández Wagner, 1999, p. 125). Así se convertirían en una de las más importantes políticas adoptadas por el régimen para imponer el tan ansiado orden a la sociedad; sustentado por las élites, delineado por expertos y ejecutado por el Estado.

Figura 1. Intervención sobre el plano que ubicaba las áreas marginadas según el Plan Director, al cual se añadieron los proyectos de vivienda mencionados previamente.

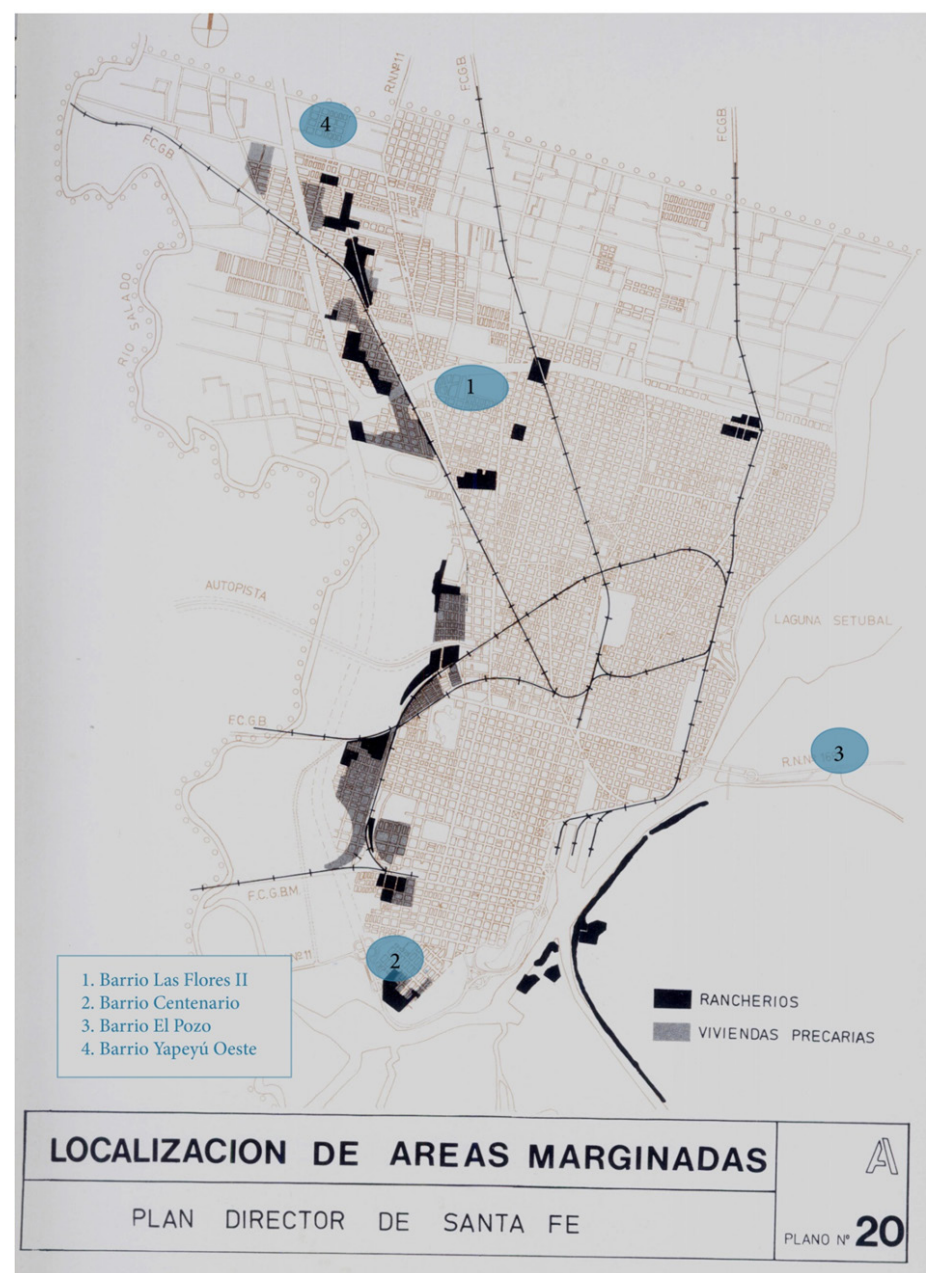


Rausch, Citroni y Manassero. Orden y violencia: políticas espaciales de la última dictadura militar argentina en Santa...

\section{Clubes de campo y barrios privados: un nuevo orden para la periferia santafesina}

Los procesos de configuración de la periferia santafesina, que tuvieron lugar a partir de la segunda mitad de la década de 1970 y hasta mediados de la década de 1980, evidencian otra de las facetas de las políticas espaciales de la última dictadura militar. Jajamovich y Menazzi (2012) señalan que la impronta espacial de este período se explica por la yuxtaposición de políticas urbanas y lógicas heterogéneas, pero, al mismo tiempo se debe a la intervención de actores guiados por lógicas e intereses económicos.

En este apartado se analizan los proyectos de barrios residenciales suburbanos, estilo country club, construidos en el margen oeste de la ciudad bajo la jurisdicción del municipio de Santo Tomé. En el período mencionado se radicaron en la zona tres complejos residenciales: "La Tatenguita", "E1 Paso" y "El Pinar"21, en cercanía a la autopista Santa Fe-Rosario (Fig. 2). Sostenemos que la configuración de este nuevo orden socioespacial se llevó a cabo a partir de políticas espaciales y de regulación del suelo, que favorecieron al capital privado e instauraron una lógica mercantilista en la producción del espacio. En términos del esquema planteado por Canelo (2016), las acciones del Estado coincidirían, en este caso, con las ideas representadas por la fracción más liberal de la dictadura militar.

Figura 2. Esquema de ubicación de los tres complejos en proximidad a la autopista

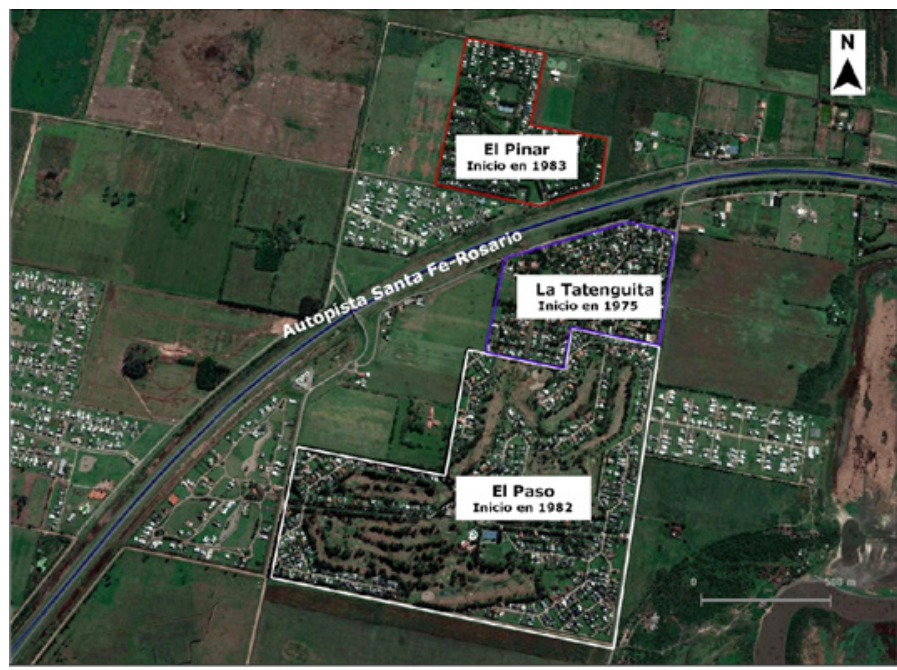

Fuente: elaboración propia sobre una imagen Landsat 2018- Google Earth.

El desarrollo del country como producto exclusivo y privativo de los sectores sociales más altos, se vinculó en estos años al ascenso de una elite corporativa, como consecuencia de las políticas económicas implementadas durante el período dictatorial. Gaggero e Iramain (2016, p. 31) señalan que los grupos empresariales nacionales

\footnotetext{
${ }^{21}$ Los tres emprendimientos históricos que se trabajan aquí fueron los primeros barrios residenciales
} construidos en la zona, que presenta una gran expansión en la actualidad. 
fueron los ganadores del modelo económico, en un contexto institucional que "hizo que las relaciones políticas entre los empresarios y los elencos gubernamentales se transformaran en un activo clave para los propietarios de los principales grupos locales". De esta manera, los sectores más favorecidos emergieron como nuevos consumidores de bienes exclusivos y asociados a la vivienda.

A partir de la década de 1970, siguiendo a Ballent (1998), se produjo una extensión del mercado de consumo de estos espacios de habitabilidad hacia sectores de la clase media alta beneficiados por las políticas económicas de la última dictadura argentina. Adquirir estos bienes significaba para los nuevos consumidores la apropiación de símbolos de distinción vinculados a un "estilo de vida country", centrado en la vivienda de fin de semana para esparcimiento y descanso (Svampa, 2001). Los primeros emprendimientos de este tipo construidos en Santa Fe y su área de influencia se localizaron en una zona rural del municipio de Santo Tomé, limítrofe al municipio santafesino. En términos urbanísticos, la construcción estos barrios no puede considerarse un hecho aislado, sino que se enmarcó en un contexto de expansión de la trama urbana y de preocupación por la conectividad, tal como fue plasmado en 1980 en el Plan Director ${ }^{22}$.

Asimismo, durante la segunda mitad del siglo XX se concretaron en la región importantes obras de vialidad, como el túnel subfluvial, la avenida de circunvalación Sur, el viaducto Oroño y la autopista Santa Fe-Rosario (Saus, 2013). Esta última fue fundamental para el desarrollo de los barrios suburbanos, ya que permitió la conexión entre la periferia rural y las ciudades lindantes (Santa Fe y Santo Tomé), posibilitando la urbanización en la zona. La vía rápida había comenzado a construirse en 1966, durante la gestión de Aldo Tessio en la gobernación de Santa Fe y se habilitó en $1972^{23}$. Sin embargo, la inundación de 1973 afectó severamente el puente sobre el río Salado, por lo que éste comenzó a reconstruirse en $1975^{24}$.

El primer barrio construido en proximidad a la autopista corresponde a $L a$ Tatenguita, cuyo proyecto fue presentado en el año 1975. Éste fue impulsado por sectores vinculados al poder militar, específicamente empresarios inmobiliarios y ex militares, que poseían tierras en la zona y propusieron la realización del proyecto a la comisión directiva del club de fútbol Unión de Santa Fe, institución que auspició el emprendimiento (Lovaisa, 2016) ${ }^{25}$. El proyecto consistía en la urbanización de 34 hectáreas que se llevaría a cabo a partir de un acuerdo con el club patrocinador, el cual se encargaría de la comercialización de los lotes y del mantenimiento de la infraestructura deportiva $^{26}$. Se trataba de una iniciativa novedosa para la región, tanto en su diseño

${ }^{22}$ Debe mencionarse como antecedente el proceso de suburbanización sobre el margen este de la ciudad de Santa Fe (Colastiné y Rincón), el cual se estructuró a partir de la Ruta Provincial No 1 y fue incluido tardíamente en el ya mencionado Plan (Rausch, 2010).

${ }^{23}$ Habilitose la autopista de Santa fe a Rosario. (4 de octubre de 1972).El Litoral, pp. 1-2.

${ }^{24}$ El nuevo puente sobre el Salado y las proyecciones de una gran obra. (30 de marzo de 1975).El Litoral, p. 3.

${ }^{25}$ La denominación La Tatenguita refiere a dicho club deportivo, apodado "El Tatengue".

${ }^{26}$ La Tatenguita: conjunto residencial - deportivo de novedosa y moderna concepción urbanística y práctica. (3 de noviembre de 1975). El Litoral, p. 7. 
Rausch, Citroni y Manassero. Orden y violencia: políticas espaciales de la última dictadura militar argentina en Santa...

urbanístico como en su funcionalidad: reunir lotes para viviendas (para uso habitacional o recreativo durante los fines de semana) con espacios deportivos comunes ${ }^{27}$. La idea de innovación fue destacada por el diario El Litoral en un artículo de 1975, en el cual se presentaba al conjunto habitacional como "único" en el país y se hacía referencia en la belleza paisajística que lo caracterizaría y a la potencial valorización que sufriría la zona. Asimismo, el artículo destacaba su cercanía a los centros urbanos y su ubicación: "Los accesos al lugar son fáciles por los caminos rurales de la zona y tiene acceso directo a la autopista sin que se desvirtúen las características de esta útil vía de comunicación" ${ }^{28}$.

Cabe señalar que el emprendimiento comenzó a promocionarse y a construirse a pesar de los problemas que suponía la obra inconclusa del puente de la autopista sobre el Río Salado. La rehabilitación del mismo se llevó a cabo cuatro años más tarde, en 1979, bajo el gobierno de facto de Jorge Desimoni ${ }^{29}$. El discurso de modernización e innovación, que sustentaba la promoción de este proyecto, sería luego característico del gobierno militar, autodefinido como proyecto modernizador y refundacional. En tal sentido, podría decirse que la concepción modernizadora sobre este espacio, que en este caso implicaba la construcción de nuevas formas urbanísticas y habitacionales exclusivas, representaba en cierta medida los intereses de los sectores de poder político y económico en Santa Fe.

El segundo emprendimiento construido en la zona fue El Paso, cuyo proyecto se inició a principios de los años ' 80 , y se presentó en 1982. Su construcción fue impulsada por los empresarios que habían construido La Tatenguita, otros empresarios de Santa Fe y algunas figuras jerárquicas del Club Atlético Unión de Santa Fe. En este caso, se trataba de un proyecto de mayor extensión —ubicado en la zona rural aledaña al anterior- que consistía en la realización de un loteo de tipo country club, donde se diseñaría una cancha de golf junto con viviendas particulares. Se trataba de un complejo más exclusivo, destinado a la recreación, a la práctica de ese deporte y a la socialización de las clases más solventes de Santa Fe y Santo Tomé.

Finalmente, el último de los complejos corresponde a El Pinar, proyecto iniciado también a principios de los ' 80 (la constitución de la Sociedad civil data de 1983), cuando se unificaron varios terrenos con el fin de realizar un loteo mayor en la zona rural del municipio. En este caso, según expresaba la escritura original, el proyecto de urbanización preveía la construcción de un club de campo con zonas aptas para el esparcimiento y práctica de deportes de uso común y zonas de parcelas para uso exclusivo por parte de los asociados.

Los dos primeros barrios tienen en común que fueron impulsados por los mismos sectores de poder económico, pero a su vez presentan algunas diferencias. En el caso de La Tatenguita, se trataba de un proyecto que mantenía ciertos componentes

\footnotetext{
${ }^{27}$ Según el testimonio de uno de los arquitectos que diseñó el complejo, las ideas urbanísticas que lo sustentaban eran novedosas para el urbanismo local. Estas ideas se habían utilizado en la década de 1960 para urbanizar estaciones turísticas del Mar Mediterráneo en Francia, país en el cual el arquitecto había trabajado y se había formado.

${ }^{28}$ (18 de junio de 1979). El Litoral, p. 6

${ }^{29}$ Un anuncio alentador para el barrio centenario. (18 de junio de 1979). El Litoral, p. 6.
} 
asociados a lo popular, en la medida de que los lotes de la urbanización serían vendidos y ofrecidos a los propios socios del club de fútbol. Por otra parte, en sus comienzos, esta urbanización reunía elementos del modelo de suburbio abierto de tipo norteamericano, junto con elementos de club cerrado ${ }^{30}$. Más bien, podríamos decir que se gestó como un espacio indefinido que no se amoldaba estrictamente a las categorías consolidadas con posterioridad. En cambio, en el caso de El Paso, se buscó ofrecer un producto más exclusivo, cuyo mayor rasgo de distinción era su diseño centrado en la práctica del golf, deporte tradicionalmente asociado a las clases altas, lo que implicó una diferenciación del caso anterior. Por otra parte, junto con El Pinar, ambos se constituyeron desde un comienzo como complejos cerrados-privados, presentados como un todo indivisible y con un perímetro cercado, dentro del cual las calles serían para la circulación privada y los vecinos debían pagar expensas.

Estas ambigüedades y diferencias se deben, en parte, a que la puesta en marcha de los tres proyectos en las décadas de 1970 y 1980 se llevó adelante en un contexto de vacío normativo tanto a nivel municipal, como a nivel provincial y nacional. Al igual que ocurrió en otras jurisdicciones del país, la inexistencia de legislación no impidió el desarrollo de urbanizaciones de este tipo, sino más bien hizo que éstas se expandan en un contexto de liberalización. Algunos autores han hecho referencia a conceptos como el de laissez-faire territorial (Torres, 2000) o el de facilitación institucional (Ríos, 2017) para hacer mención del rol del Estado en la construcción de clubes de campo y barrios cerrados.

En el caso de la provincia de Santa Fe, la regulación se delegó a los municipios y se recurrió a diversas figuras jurídicas, aunque todas presentaban inconvenientes y no lograban encuadrarse en ningún derecho real existente hasta el momento (Gerard, 2009). De hecho, ninguno de los tres barrios de Santo Tomé contó con un expediente de urbanización aprobado, sino que fueron aceptados de hecho por parte del municipio y se hicieron adaptaciones a otras normativas urbanas (Pallud, 2010). Es preciso mencionar que en estos años, el municipio de Santo Tomé no contaba con un plan urbano integral, sino que la gestión urbana dependía de un conjunto de normas — como los reglamentos de zonificación, urbanización y edificaciónque abarcaban diversos aspectos de forma fragmentaria.

En 1979 se sancionó la ordenanza No 818 sobre Usos del Suelo ${ }^{31}$, durante la intendencia de facto de César Luis Rey Leyes (1976-1981). Esta ordenanza fue la primera normativa que mencionaba estos emprendimientos e incluía dentro de los usos del suelo del ejido del municipio un "Área de residencia transitoria suburbana" la cual comprendía "los 'clubes privados', comúnmente denominados 'countries" (Ord. N 818/79). Aunque la ordenanza explicitaba la intención de reglamentar en el corto plazo, la situación de vacío normativo se mantuvo hasta el año $1987^{32}$.

${ }^{30}$ El barrio fue mensurado bajo el régimen de subdivisión simple, es decir cediendo las calles públicas y los espacios verdes al municipio (Pallud, 2010).

${ }^{31}$ Ordenanza N ${ }^{\circ} 818$ del de 22 de octubre de 1979. Usos del suelo. Municipalidad de Santo Tomé, Santa Fe.

${ }^{32}$ En 1987 se sancionó la Ordenanza No 1337 durante la intendencia de Juan Carlos Nava (1983-1987). Esta normativa reconocía por primera vez la figura del "Club de Campo" dentro del municipio y puede considerarse un punto de inflexión relevante, en la media que otorgaba legitimación a un proceso que había comenzado hacía tiempo. 
Rausch, Citroni y Manassero. Orden y violencia: políticas espaciales de la última dictadura militar argentina en Santa...

A partir lo expuesto, puede decirse que las políticas llevadas adelante por la última dictadura militar, en relación con estas urbanizaciones, evidenciaron una ausencia estratégica de planificación urbana y una fuerte desregulación — traducida en una facilitación- para el desarrollo de las mismas. De esta forma, el nuevo orden de la periferia urbana definió un espacio para la acumulación, constituido en beneficio del capital privado y de sectores empresariales, algunos vinculados directamente al gobierno militar. Estas transformaciones, basadas en la mercantilización del espacio y el realce de lo privado, mostraron los primeros atisbos espaciales de una creciente hegemonía liberal que acompañaba la ideología y las políticas económicas que se estaban implementando desde el Ministerio de Economía.

\section{El Proyecto Hidroeléctrico Paraná Medio: civilizar el territorio nacional y defender sus límites}

La reconfiguración del territorio a escala regional fue uno de los objetivos de la última dictadura argentina y se materializó en grandes proyectos de infraestructura como autopistas, puentes y centrales generadoras de energía. Según han señalado Salamanca y Colombo (2019, p. 31), "los proyectos diseñados y realizados a gran escala son la expresión del militar planificador que zonifica, prioriza, y ordena la ciudad y el territorio con la idea de educar y reformar la sociedad", pero también para "promover una idea de soberanía y de exaltación del territorio nacional". Para el caso del PHPM, objetivos económicos vinculados a la explotación de recursos naturales (en especial la búsqueda de una alternativa al petróleo ${ }^{33}$ ) se acompañaron de objetivos políticos, consistentes en el control espacial, la exaltación de un Ser nacional y en la legitimación del régimen autoritario ${ }^{34}$.

El PHPM fue uno de los emprendimientos más emblemáticos del Proyecto Nacional que tuvieron las Fuerzas Armadas durante la última dictadura militar. Si bien nunca se concretó ${ }^{35}$, fue un proyecto intensamente promovido por la fracción más "dura" de este gobierno, liderada a nivel nacional por el general Ramón Díaz Bessone, ministro del Ministerio de Planeamiento (MP). Esta fracción, de ideología estatista y desarrollista, antagonizaba con las ideas liberales de las otras fracciones, y sobre todo, con las políticas que se intentaban implementar desde el Ministerio de Economía (Canelo, 2016). En Santa Fe, puede decirse que la obra hidroeléctrica funcionó como artefacto ideológico de la antipolítica (Canelo, 2016) llevada adelante por este Ministerio y fue apoyada fervientemente por algunos sectores sociales, tales como empresarios, la Bolsa de Comercio de Santa Fe, sindicatos (en especial Luz y Fuerza), el Colegio de Ingenieros, y funcionarios del gobierno, entre otros.

\footnotetext{
${ }^{33}$ Téngase en cuenta que por esos años el mundo enfrentaba la llamada crisis del petróleo.

${ }^{34}$ Este proyecto fue alentado desde varios sectores sociales y políticos con intereses diversos, incluso contrapuestos. En este artículo nos concentramos en la promoción que hizo el gobierno dictatorial del mismo y sus objetivos políticos al proponerlo como proyecto nacional.

${ }^{35}$ En 1995, bajo la presidencia de Carlos Menem (1989-1999) el proyecto fue retomado con algunas modificaciones.
} 
El embalse proyectado sobre el río Paraná se encontraba definido por un cierre norte, a la altura de la ciudad de Goya (Corrientes) y por otro al sur, que cruzaba de Santa Fe a Entre Ríos por la isla Chapetón, a la altura de Villa Urquiza (Entre Ríos), recorriendo $630 \mathrm{~km}$ a lo largo del cauce. Mediante ambas centrales hidroeléctricas ubicadas en cada cierre, estaba previsto generar energía por una media anual total de entre $33 \mathrm{mil} \mathrm{GW/h} \mathrm{y} 48 \mathrm{mil} \mathrm{GW/h}$. Según cálculos estimados, la obra iba a insumir 230 millones de metros cúbicos de material (Reyes Giménez, 1982), constituyéndose en una de las represas más grandes del mundo. El emprendimiento seguía una fórmula muy utilizada en esas décadas para este tipo de proyectos, donde la función principal de generación energética se complementaba con otras obras como: 1) infraestructura ferro-vial de comunicación regional, nacional e internacional ${ }^{36}$; 2) obras de navegación; 3 ) infraestructura de riego en algunas áreas, para el desarrollo de la agricultura; 4) obras de estímulo al turismo; y 5) obras para la preservación y desarrollo de la fauna ictícola —destinada a la producción y el turismo- (AyEE, 1978).

El proyecto tenía larga data en las agendas e intenciones de los gobiernos precedentes. Originalmente, había sido iniciativa del gobierno dictatorial de Pedro Aramburu (1955-1958) ${ }^{37}$ —atendiendo a recomendaciones de Raúl Prebisch (1955) ${ }^{38}$ aunque las discontinuidades institucionales y políticas en Argentina condujeron a que recién en 1975 el mismo fuera declarado "de prioridad nacional" 39 , respondiendo a los objetivos planteados en el Plan Nacional de Desarrollo y Seguridad 1971-1974. En este Plan, se proponía una estrategia de modernización (a través de la urbanización y la industrialización) basada en el aprovechamiento de los recursos naturales, en especial, de las cuencas hídricas para la generación de energía hidroeléctrica (Rausch, 2016). A nivel internacional, tales objetivos se articulaban con los proclamados, casi una década antes, en el Tratado de la Cuenca del Plata (TCP). Hacia finales de la década de 1970, si bien las iniciativas del Tratado no habían tenido aplicación, las ideas y objetivos sobre organización económico-territorial de los ríos pervivieron en las propuestas espaciales que planteaba el proyecto hidroeléctrico ${ }^{40}$.

Con el PHPM, y en especial con el cierre sur Chapetón, el gobierno dictatorial pretendía conformar un "polo de desarrollo" (Lambruschini, 1979, p. 29) en el área central de Argentina, y en particular, conectar a la ciudad de Santa Fe internacionalmente, a través de la salida al océano Atlántico. En el esquema de organización territorial propuesto por el Plan Director, compuesto por un sistema ferro-vial de escala regional, el emprendimiento hidroeléctrico funcionaba como un nodo infraestructural energéticoconector de las escalas regional e internacional (Fig. 3).

\footnotetext{
${ }^{36}$ Municipalidad de Santa Fe, Secretaría de Obras Públicas. Red de enlace ferrovial del área de influencia de la presa del Paraná Medio, cierre sur-Chapetón. Santa Fe, octubre 1981. Consultado el 9 de mayo de 2012 (AGP). Esta propuesta puede verse en el Plan Director de Santa Fe, Plano No 33.

${ }^{37}$ Decreto Ley $\mathrm{N}^{\circ} 11.955$, ratificado por Ley Nacional $\mathrm{N}^{\circ} 14.467$ del 5 de noviembre de 1958.

38 Prebisch, entonces director de la CEPAL, consideraba dar impulso a la industria nacional reforzando el sistema energético a través de la construcción de aprovechamientos hidroeléctricos.

${ }^{39}$ PEN. Decreto No 1.447 del 30 de mayo de 1975.

${ }^{40}$ Las mismas se encuentran sistematizadas en el Plan Director de Santa Fe (1980).
} 
Rausch, Citroni y Manassero. Orden y violencia: políticas espaciales de la última dictadura militar argentina en Santa...

Figura 3. EI PHPM y las comunicaciones ferroviales.

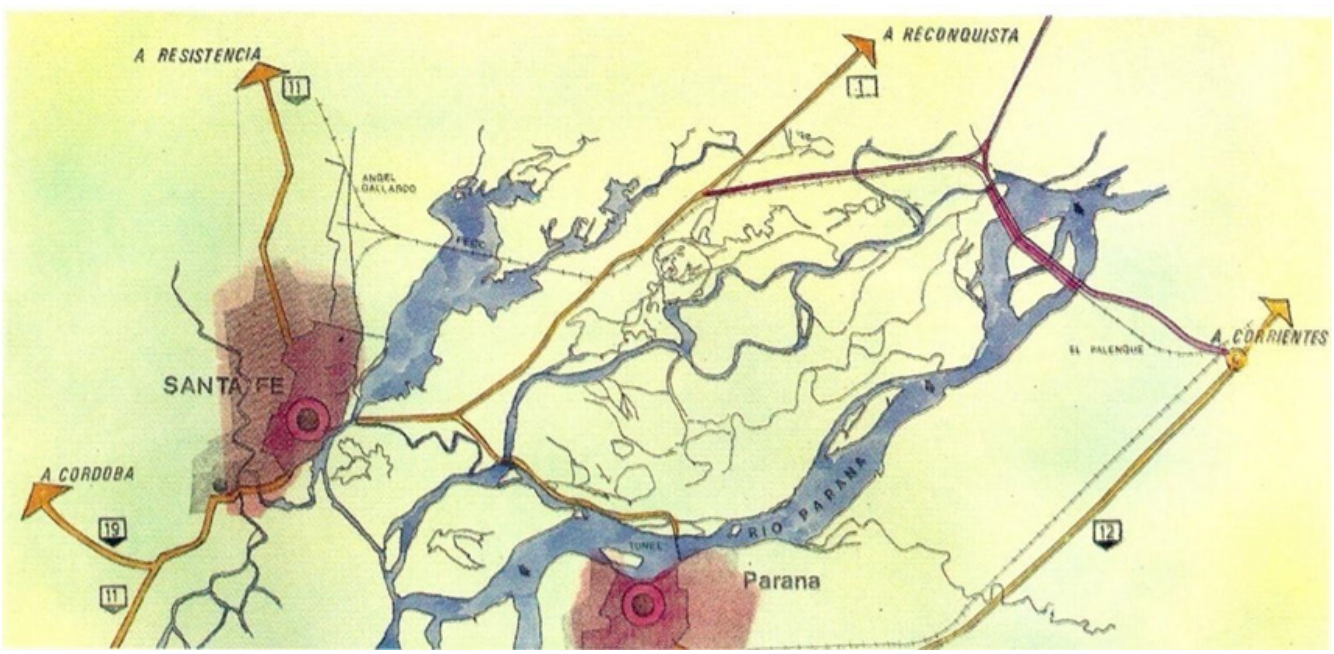

Fuente: AyEE, Aprovechamiento hidroeléctrico Paraná Medio, 1983, s/n.

A partir de ser considerado un proyecto nacional prioritario, la empresa estatal Agua y Energía Eléctrica (AyEE) inició vinculaciones con un equipo de técnicos de la URSS $^{41}$, través de la Jefatura Estudios y Proyectos Paraná Medio, oficina creada por AyEE para el desarrollo del emprendimiento, que por ese entonces tenía su sede en la ciudad de Santa Fe. En 1976 se concluyó el anteproyecto ${ }^{42}$ y en 1978, el gobierno ratificó los convenios con la URSS, contratando a la empresa Technopromexport para la asistencia financiera y técnica de las obras ${ }^{43}$. Durante ese año, la empresa soviética se dedicó a revisar y evaluar los estudios de prefactibilidad realizados antes por AyEE ${ }^{44}$.

Los años 1978 y 1979 fueron especialmente intensos en actividades de difusión pública de la obra en las ciudades de Santa Fe y Paraná. Además de ocupar amplios espacios en la prensa local, el proyecto convocaría a una diversidad de actores sociales en reuniones públicas y conferencias. A partir de las elaboraciones discursivas, por las cuales se promocionaba el emprendimiento, se evidencia cómo fue concebido el mismo, en tanto infraestructura territorial de importancia geopolítica, pero también su condición de artefacto técnico-ideológico en un momento histórico sesgado por el conflicto y la violencia, incluso en el interior del gobierno dictatorial. Como se mencionó antes, el Paraná Medio fue un proyecto de la fracción estatista de la dictadura, que actuaba principalmente a través del Ministerio de Planeamiento. Los discursos en torno al proyecto estaban en clara sintonía con la visión decadentista de esta fracción

${ }^{41}$ Durante esos años, el gobierno dictatorial mantenía relaciones comerciales con la URSS, principalmente en torno a la exportación de cereales (Fuentes, 2006; Gilbert, 1994).

${ }^{42}$ Beretta, M. (11 de junio de 1979). El Proyecto Paraná Medio: los técnicos soviéticos evaluaron el aprovechamiento energético. El Litoral.

${ }^{43}$ PEN. Ley No 21.614 del 5 de agosto de 1977 y Decreto Nacional No 2.648 del 6 de noviembre de 1978.

${ }^{44}$ Beretta, M. (11 de junio de 1979). El Proyecto Paraná Medio: los técnicos soviéticos evaluaron el aprovechamiento energético. El Litoral. 
y sus intenciones refundacionales ${ }^{45}$. En efecto, dichas elaboraciones hacían énfasis en la construcción nacional, que se apoyaba en tres nociones: el territorio nacional, la infraestructura y los recursos naturales (Rausch, 2019). Estas nociones, a su vez, se integraban a las ideas de fortalecer el "Ser nacional" para su "engrandecimiento" (Paganini, 1979, p. 27).

La cuestión geopolítica ocupó un lugar clave en el desarrollo del proyecto hidroeléctrico. Para los militares, la geopolítica era considerada "uno de los instrumentos esenciales" del proyecto nacional (Lambruschini, 1979, p. 28) y tenía una de sus manifestaciones principales en la organización tecnológica del territorio. Así, el PHPM se integraba en un Plan territorial más amplio que incluía un proyecto de canalizaciones en el río Bermejo y otro de aprovechamiento del Iberá ${ }^{46}$. Mediante estas tres obras, y otras complementarias (viales y ferroviales), se buscaba la navegación continua y el control de las inundaciones, pero también civilizar, ocupar y controlar (tanto material como ideológicamente) el espacio: “el desarrollo de la región, la conquista y la incorporación de tierras a la cultura occidental y al mundo cristiano, [pero] que ha sido frenado durante largos años por desencuentros internos" (Lambruschini, 1979, p. 28). Como expresara el comandante en jefe de la Armada, la intención estaba puesta en "ocupar los espacios vacíos" y en "explotar los recursos naturales" (Lambruschini, 1979, p. 32), más precisamente en "cubrir los límites” territoriales y “equilibrar el país” (Paganini, 1978, p. 24).

El control territorial que este gobierno buscaba a partir de este Plan quedaba asimismo en evidencia, en los objetivos que le eran atribuidos al PHPM dentro de la Cuenca del Plata: llevar lo más al Norte posible la nueva línea de equilibrio político (Camba, 1979), lo cual representaba la posibilidad de neutralizar la "presión extranjera"47 (De Nevares, 1978) y la conformación de un "área pivote" de desarrollo que también funcionara como base de operaciones geoestratégicas (Camba, 1979; De Nevares, 1978).

Este rol territorialmente estratégico que tuvo el PHPM para la fracción dura de la última dictadura militar debe ponderarse a la luz del aparato represivo desplegado por este gobierno, así como también de los conflictos suscitados con los países limítrofes, en especial con Brasil y Chile. En primer lugar, las ideas de reconstrucción nacional, desarrollo e independencia — con las cuales se promocionaba el emprendimientointentaban crear consenso social, legitimación del régimen autoritario e idea de unidad nacional frente a la persecución de la disidencia política que se estaba llevando adelante en el país. En segundo lugar, deben contemplarse las disputas que en esos años el gobierno dictatorial tuvo con Chile por la posesión de un conjunto de islas en el Canal de Beagle,

\footnotetext{
${ }^{45}$ Como desarrolla Canelo (2016, p. 77), esta fracción consideraba que el Proyecto de la generación del 80 había entrado en decadencia con el surgimiento de la sociedad de masas y consideraban que su misión era retomar aquel proyecto de elites a través de la conformación de una "nueva generación del Ochenta".

${ }^{46}$ Herencia de las propuestas del TCP.

${ }^{47}$ Haciendo referencia a Brasil. La fracción de la dictadura que promocionaba el PHPM tenía vinculaciones con la URSS y antagonizaba con EEUU, considerando a Brasil un instrumento de su política imperialista (Gilbert, 1994).
} 
Rausch, Citroni y Manassero. Orden y violencia: políticas espaciales de la última dictadura militar argentina en Santa...

situación que estuvo cerca de la declaración de guerra ${ }^{48}$. Junto a estas dos situaciones, se desarrollaba el conflicto en el interior mismo del gobierno, donde la fracción estatista y con vinculaciones con la URSS defendía políticas que antagonizaban francamente con las otras fracciones (aperturistas, de corte liberal y adherente a las recomendaciones del Fondo Monetario Internacional), de lo cual se desprendía asimismo, el antagonismo con Brasil, asociado a las políticas estadounidenses. De ahí, que el PHPM puede considerarse una pieza clave de las políticas territoriales promovidas por el Ministerio de Planeamiento de la última dictadura militar, en una actitud defensiva que tuvo esta fracción, frente a la creciente hegemonía del Fondo Monetario Internacional y a la desvinculación del gobierno con la URSS, lo cual redundó en la desfinanciación del proyecto y su imposibilidad de concreción.

\section{Conclusiones}

En este artículo se han abordado parte de las políticas espaciales adoptadas por la última dictadura militar en la ciudad de Santa Fe y su área de influencia, con manifestación en una serie de propuestas de carácter urbano y suburbano. Como se ha mencionado al inicio, esta dictadura tuvo características singulares, sustentadas en los objetivos de refundación nacional que se nutría de un plan de exterminio de la disidencia política. Esta lógica que puede leerse en la dinámica orden/violencia tuvo, como se observa en los casos estudiados, sus manifestaciones espaciales en diversas propuestas de obra pública y privada dentro de la ciudad y el territorio ampliado.

De modo general, puede decirse que las políticas espaciales llevadas adelante en Santa Fe, y área de influencia, no difieren en lo fundamental de las adoptadas por los gobiernos de otras ciudades (Svampa, 2001; Águila, 2008; Jajamovich y Menazzi, 2012; Oszlak, 2017; Gomes, 2018; Salamanca Villamizary Colombo, 2019). Esto puede vincularse al carácter centralizador —en el gobierno nacional - que tuvo esta dictadura, pero también en los objetivos políticos y modernizadores que orientaban las propuestas.

Como dan cuenta estudios específicos (Salamanca Villamizar y Colombo, 2019), en el plano de la obra pública, este gobierno se diferenció de los anteriores en la magnitud que tuvieron los cambios en el espacio urbano y el territorio. Si bien muchas de las obras concretadas en este período habían sido formuladas en períodos anteriores, incluso en gobiernos elegidos democráticamente, esta dictadura los llevó a su concreción como parte de su plan de transformación social, a través de una gestión que se presentaba como "el bien común"; o bien, como ha señalado Oszlak (2017, p. 375), en tanto "intérprete de una voluntad no expresada, inmanente, de una suerte de mayoría silenciosa, de una burguesía urbana cuyos deseos y anhelos más recónditos parece conocer". Junto a ello, la ausencia de movilización social y de instancias de discusión democrática favoreció la ejecución rápida, sin mediaciones y muchas veces violenta, de grandes obras con alto impacto socioterritorial, como fue el caso de los barrios de vivienda de interés social y las autopistas. No obstante, en Santa Fe, el plan de obras propuestas en el Plan Director,

\footnotetext{
${ }^{48}$ El recorrido documentado por el conflicto puede verse en: Rossi de Flory (1984).
} 
que implicaba una transformación drástica de la estructura urbana y sus dinámicas, tuvo una concreción parcial y fragmentada, con énfasis en lo normativo pero con menor manifestación material de los proyectos. Esta "volatilidad de los planes" ha sido una de las características históricas de los planes urbanos en Santa Fe (Fedele, 2011) y el período entre 1976 y 1983 no constituyó una excepción.

Por otra parte, como demuestra el análisis de los diferentes proyectos, las políticas espaciales llevadas adelante durante esta dictadura se presentaron con carácter heterogéneo - incluso ideológicamente contradictorios - en relación a la complejidad y diversidad de actores e intereses que conformaban las dinámicas territoriales, así como por la composición heterogénea del mismo gobierno. En efecto, si por un lado el PHPM representaba el ideal desarrollista (de la fracción más dura de la dictadura) y constituía una proyecto resultante de la inercia nacionalista y de las relaciones comerciales con la URSS; por el contrario, los proyectos de barrios suburbanos tipo jardín ya estaban perfilando nuevos ideales, vinculados a la sociedad individualista y neoliberal, así como también a las relaciones con el Fondo Monetario Internacional que el Ministerio de Economía estaba fortaleciendo.

A pesar de tales diferencias y contradicciones, puede decirse que las políticas espaciales de la última dictadura militar argentina alcanzaron grados de coherencia en la voluntad de modernización y profunda transformación del espacio urbano santafesino y regional (no siempre concretada materialmente) que se llevó adelante a través de estrategias y procedimientos específicos, consistentes en la creación de instituciones y disposiciones, en la difusión de un cuerpo discursivo orientado a crear consenso social y en prácticas espaciales (los proyectos) que constituyeron sus manifestaciones más evidentes.

\section{Fuentes}

Agua y Energía Eléctrica, Aprovechamiento hidroeléctrico Paraná Medio, 1983, s/n. Beretta, M. (11 de junio de 1979). El Proyecto Paraná Medio: los técnicos soviéticos evaluaron el aprovechamiento energético. El Litoral.

Decreto Ley $\mathrm{N}^{\circ} 11.955$, ratificado por Ley Nacional $\mathrm{N}^{\circ} 14.467$ del 5 de noviembre de 1958 . Decreto Nacional No 2.648, 6 de noviembre de 1978.

Decreto provincial, Santa Fe, No 3217,13 de octubre.

Decreto provincial, Santa Fe, N 9774, 29 de diciembre de 1967.

Decreto provincial, Santa Fe, No 3869, 25 de noviembre de 1976.

Ley nacional $\mathrm{N}^{\circ} 17605$, Plan de promoción social, construcción y financiación de viviendas. Ley Nacional No 19929 del 3 de noviembre de 1972. Creación del Fondo Nacional de la Vivienda. Ley Nacional No 21581, 26 de mayo de 1977. Régimen de financiamiento del Fondo Nacional de la Vivienda.

Municipalidad de Santa Fe, Secretaría de Obras Públicas. Red de enlace ferrovial del área de influencia de la presa del Paraná Medio, cierre sur-Chapetón. Santa Fe, octubre 1981. Consultado el 9 de mayo de 2012 (AGP). 
Rausch, Citroni y Manassero. Orden y violencia: políticas espaciales de la última dictadura militar argentina en Santa...

Ordenanza Municipal, Santa Fe, N 7192,5 de agosto de 1976.

Ordenanza Municipal, Santa Fe, N 7552, 9 de octubre de 1978.

PEN. Decreto No $1.447,30$ de mayo de 1975.

PEN. Ley N $\mathrm{N}^{\mathrm{O}} 21.614,5$ de agosto de 1977.

Resolución Dirección Provincial de Vivienda y Urbanismo, Santa Fe, 16399, 26 de julio de 1978.

\section{Referencias bibliográficas}

Águila, G. (2008). Dictadura, represión y sociedad en Rosario, 1976/1983. Un estudio sobre la represión y los comportamientos y actitudes sociales en dictadura. Buenos Aires: Prometeo.

Alonso, L. y Citroni, J. (2008). "Intervenciones en la zona céntrica santafesina en época de dictadura: interacciones y conflictos". Cuaderno Urbano, VII (7), pp. 75-92.

Baliero, H. (coord.) (1983). Desarrollo urbano y vivienda. Introducción al estudio de la acción del Estado. Buenos Aires: Subsecretaría de Desarrollo Urbano y Vivienda - Ministerio de Acción Social de la Nación.

Ballent, A. (1998). "Country life: los nuevos paraísos, su historia y sus profetas". Block. Revista de cultura de la arquitectura, la ciudad y el territorio, 2, 88-101. ISSN: 0329-6288.

Ballent, A. (2004). "Vivienda de interés social". En J. F. Liernur\& F. Aliata (dirs.), Diccionario de arquitectura en la Argentina. Estilos, obras, biografías, instituciones, ciudades, tomo S-Z, (pp. 176-187). Buenos Aires: AGEA.

Ballent, A. (2009). Las huellas de la política. Vivienda, ciudad, peronismo 1943-1955. Buenos Aires: Prometeo/UNQ.

Ballent, A. (2014). "Instituciones y planes, del Banco Hipotecario Nacional al Fondo Nacional de la Vivienda". En A. Ballent \& J. F. Liernur, La casa y la multitud. Vivienda, politica y cultura en la Argentina moderna, (pp. 285-317). Buenos Aires: FCE.

Brites, W. \& Catullo, M. (2016). "Represas y transformación socio-urbana. Un análisis comparativo de los proyectos hidroeléctricos de Salto Grande y Yacyretá". Cidades. Comunidades e Territórios, 33, pp. 50-67.

Camba, F. (1979). "Aspectos ferro-viales". En Universidad Nacional del Litoral, Segundas Jornadas del Paraná Medio, (pp. 37-93). Santa Fe: UNL.

Canelo, P. (2016). La política secreta de la última dictadura argentina (1976-1983). Buenos Aires: Edhasa.

Citroni, J. (2011). "Modos de control del espacio urbano en un contexto de poder autoritario. El caso de Santa Fe, Argentina, 1976-1981". Urbano, 14(24), pp. 70-81.

Citroni, J. (2019). "Reflexiones a 50 años de planeamiento municipal". D1 Revista Origen, 10, pp. 58-63. ISSN: 1852-9674.

Cuenya, B. (1992). "Políticas habitacionales en la crisis: el caso de Argentina". Vivienda, 3(3), pp. 36-45.

De Nevares, M. (1978). “El Paraná Medio en la Cuenca del Plata”. Realidad Económica, 32 , pp. 18-24.

Fedele, J. (2011). El río en la ciudad del plan. Urbanismo sobre las riberas de la pampa argentina, primera mitad del siglo XX. Santa Fe: Ediciones UNL. 
Fernández Wagner, R. (1999). “Crónica de las políticas de vivienda en Argentina”. En E. Gill Nessi (comp.), Hacia un diagnóstico de la vivienda popular en Iberoamérica. Antecedentes para el debate, (pp. 122-130). Asunción: HABYTED-CYTED.

Ferrer, A. (2004). La economía argentina. Desde sus orígenes hasta principios del siglo XXI. Buenos Aires: FCE.

Fuentes, V. T. (2006). "La relación bilateral Argentina-Rusia: más que socios comerciales". Relaciones Internacionales, 15 (30), pp. 1-12.

Gaggero, A. e Iramain, L. (2016). "Estado y grupos empresarios durante la dictadura cívico-militar". Revista de la Facultad de Ciencias Sociales/ UBA, 90, pp. 28-33.

Gerard, L. (2009). "Régimen jurídico adoptado por los clubes de campo y barrios cerrados en la provincia de Santa Fe". En S. Cadoche (comp.), Clubes de campo y barrios cerrados. Algunos aportes para una futura reforma, (pp. 77-83). Santa Fe: Ediciones UNL.

Gilbert, I. (1994). El oro de Moscú. Historia secreta de la diplomacia, el comercio y la inteligencia soviética en la Argentina. Buenos Aires: Planeta.

Gomes, G. (2018). Vivienda social en dictaduras. Actores, discursos, políticas públicas y usos públicos de las Regiones Metropolitanas de Buenos Aires (1966-1983) y Santiago de Chile (1973-1989). Tesis de doctorado. Universidad de Buenos Aires, Buenos Aires.

Gutiérrez, J. J. (2016). "Del urbanismo al planeamiento: Pastor en la revista de Arquitectura (1943-1951)". Arquitecturas del Sur, 34 (50), pp. 40-51.

Jajamovich, G. \& Menazzi, L. (2012). "Políticas urbanas en un contexto de dictadura militar. Algunos interrogantes a partir de Buenos Aires (1976-1983)”. Bitácora Urbano-Territorial, 20 (1), pp. 11-20.

Lambruschini,A. (1979). “Alocución del señor miembro de la Junta Militar y comandante en jefe de la Armada, Almte. Armando Lambruschini”. En Universidad Nacional del Litoral, Segundas Jornadas del Paraná Medio, (pp. 27-34). Santa Fe: UNL.

Lovaisa, N. (2016). "Los dueños de la Tatenguita". En N. Lovaisa, Tiempo recuperado: Historias del fútbol de Santa Fe, (pp. 59-61). Santa Fe: Ediciones Lux.

Mazza, C. (2008). "De lo sublime a lo técnico. La incorporación de la noción de paisaje en el planeamiento regional en Argentina”. Perspectivas Urbanas / Urban Perspectives, 9, pp. 51-64.

Ministerio de Planeamiento. (1977). Proyecto Nacional. Documento de Trabajo.

Municipalidad de Santa Fe. (2002). Plan estratégico Santa Fe siglo XXI. Diagnóstico participativo. Santa Fe.

Oszlak, O. (2017) [1991]. Merecer la ciudad. Los pobres y el derecho al espacio urbano. Buenos Aires: EDUNTREF.

Paganini, C. (1978). "Alocución del representante del gobierno de Santa Fe, Cont. Carlos Alberto Paganini, Secretario General del COPRODE”. En Universidad Nacional de Entre Ríos, Primeras Jornadas del Paraná Medio, (pp. 24-27). Paraná: UNER. Pallud, P. (2010). "Las urbanizaciones privadas cerradas en Santo Tomé, Santa Fe". Pampa. Revista Interuniversitaria de Estudios Territoriales, 6(6), pp. 37-58. 
Rausch, Citroni y Manassero. Orden y violencia: políticas espaciales de la última dictadura militar argentina en Santa...

Pastor, J. M. (1947). Urbanismo con Planeamiento, principios de una nueva técnica social. Buenos Aires: Arte y Técnica.

Prebisch, R. (1955). La situación económica del país. Buenos Aires: Presidencia de la Nación.

Pucciarelli, A. R. (2004). "La patria contratista. El nuevo discurso liberal de la dictadura encubre una vieja práctica corporativa". En A. Pucciarelli (coord.), Empresarios, tecnócratas y militares. La trama corporativa de la última dictadura, (pp. 99171). Buenos Aires: Siglo XXI.

Rausch, G. (2010). "El Plan del 80 en Santa Fe: regionalización tardía ante una suburbanización inminente". Cuaderno Urbano, 9(9), pp. 111-129.

Rausch, G. (2016). "Estado, desarrollo y naturaleza: el caso del Proyecto Paraná Medio bajo el paradigma hidráulico nacional (Argentina 1958-1986)". Estudios Socioterritoriales. Revista de Geografía, 20, pp. 11-25. ISSN: 1515-6206.

Rausch, G. (2019). "Planificación urbana e infraestructura en tiempos violentos: la ciudad de Santa Fe (Argentina) durante la última dictadura militar". Folia Histórica del Nordeste, 36, pp. 27-50. ISSN: 2525-1627.

Reyes Giménez, A. (1982). “Paraná Medio: ¿soberanía o dependencia?’. Síntomas, 1, pp. 3-36.

Rigotti, A. M. (2003). Las invenciones del Urbanismo en Argentina (1900-1960). Tesis de doctorado. Universidad Nacional de Rosario, Rosario.

Rigotti, A. M. (2004). José Pastor y la invención del planeamiento en Argentina. Rosario: CURDIUR.

Ríos, D. (2017). “Aguas turbias: los nuevos cuerpos de agua de las urbanizaciones cerradas de Buenos Aires (Argentina)". Cuadernos de Geografía. Revista Colombiana de Geografía, 26, pp. 201-219.

Rodríguez, M. C. y Di Virgilio, M. M. (2011). "El caleidoscopio de las políticas urbanas. Un rompecabezas para armar”. En M. C. Rodríguez \& M. V. Di Virgilio (comps.), Caleidoscopio de las políticas urbanas. Un rompecabezas para armar, (pp. 1752). Buenos Aires: Prometeo.

Rossi de Flory, M. L. (1984). Argentina y Chile en la zona del Beagle. Buenos Aires: Ministerio de Educación y Justicia.

Salamanca Villamizar, C. y Colombo, P. (eds.) (2019). La violencia en el espacio. Políticas urbanas y territoriales durante la dictadura cívico-militar en Argentina (1976-1983). Rosario: UNR editora.

Saus, M. (2013). "Políticas ferroviarias del Estado y sus secuelas urbanas (Santa Fe, 1948-1989)". Cuaderno Urbano: Espacio, cultura y sociedad, 15(15), pp. 5-26.

Svampa, M. (2001). Los que ganaron. La vida en los Countries y barrios privados. Buenos Aires: Biblos Sociedad.

Torres, H. (2000). "Procesos recientes de fragmentación socioespacial en Buenos Aires: la suburbanización de las élites". Mundo Urbano, 4.

Van Poepelen, C. (2006). "El derecho al uso de la ciudad durante la última dictadura militar”. En G. Ríos (comp.), La cita secreta. Encuentros y desencuentros entre memoria y educación, (pp. 211-223). Santa Fe: AMSAFE. 
